\section{Cureus}

\title{
Functional Outcome After Decompressive Craniectomy in Patients with Dominant or Non-Dominant Malignant Middle Cerebral Infarcts
}

Bilal Kamal Alam ${ }^{1}$, Ahmed S. Bukhari ${ }^{2}$, Salman Assad ${ }^{3}$, Muhammad Siddique Pir ${ }^{4}$, Haider Ghazanfar $^{5}$, Muhammad Junaid Niaz ${ }^{6}$, Maryam Kundi ${ }^{7}$, Saima Shah ${ }^{8}$, Maimoona Siddiqui ${ }^{9}$

1. Department of Internal Medicine, Fairview Hospital, Cleveland Clinic, USA 2. Research Associate, Department of Neurology, Shifa International Hospital, Islamabad, Pakistan 3. Internal Medicine, Marshall University School of Medicine, Huntington, USA 4. Internal Medicine, The Wright Center for Graduate Medical Education, Scranton, USA 5. Internal Medicine, Shifa College of Medicine, Islamabad, PAK 6. Department of Genito-urinary Oncology, Weill Medical College of Cornell University 7. Pain Management, Institute of Advanced Medicine and Surgery, Philadelphia, USA 8. Internal Medicine, Hayatabad Medical Complex, Peshawar, PAK 9. Neurology, Shifa International Hospital, Islamabad, PAK

$\square$ Corresponding author: Salman Assad, salmanassad91@gmail.com Disclosures can be found in Additional Information at the end of the article

\section{Abstract}

Background: The use of decompressive craniectomy (DC) has been studied in the setting of different conditions, including traumatic brain injury, subarachnoid hemorrhage, and malignant middle cerebral artery (MCA) infarction. The rationale of this study is to determine the functional outcome after DC in patients with malignant MCA infarcts.

Methods: A longitudinal cohort study was performed based on patients diagnosed with malignant MCA territory infarction admitted to the Neurosurgery Department of a tertiary care hospital in Islamabad, Pakistan between July 2015 and November 2016. All patients had a clinical diagnosis of stroke according to the World Health Organization (WHO) stroke criteria.

Results: A total of 34 patients participated in this study, out of which 20/31 (64.5\%) were males while $11 / 31$ (35.5\%) were females with a mean age of $51.61 \pm 13.96$ years. The mean time from diagnosis to surgery was $60.61 \pm 49.83$ hours. Out of 31 patients, $18(58.1 \%)$ had a right middle cerebral artery infarct (RMCAI) and 13 (41.9\%) had a left middle cerebral artery infarct (LCAI). Logistic regression was applied to assess the association between the type of MCA infarct with the National Institutes of Health Stroke Scale (NIHSS), modified Rankin Scale (mRS), modified Barthel Index (mBI) scores, and upper and lower limb motor power. However, the logistic

Received 12/28/2016 Review began 01/06/2017 Review ended 01/23/2017 Published 01/26/2017

\section{(c) Copyright 2017}

Kamal Alam et al. This is an open access article distributed under the terms of the Creative Commons Attribution License CC-BY 3.0., which permits unrestricted use, distribution, and reproduction in any medium, provided the original author and source are credited. regression model was not statistically significant $\chi^{2}(4)=3.896, p=0.866$. There was a statistically significant mild improvement of neurological scores and upper and lower motor power over a course of six months, but the overall functional outcome was poor with $\mathrm{mBI}<60$ and $\mathrm{mRS}>4(\mathrm{p}<0.001)$ with total mortality of $8.7 \%$.

Conclusion: Decompressive craniectomy is a life-saving surgery that appears to benefit patients with malignant MCA infarcts of either the dominant or non-dominant cerebral hemisphere. Decompressive craniectomy results in mild improvements in neurological scores but still poor functional outcome after six months.

How to cite this article

Kamal Alam B, Bukhari A S, Assad S, et al. (January 26, 2017) Functional Outcome After Decompressive Craniectomy in Patients with Dominant or Non-Dominant Malignant Middle Cerebral Infarcts. Cureus 9(1): e997. DOI 10.7759/cureus.997 
Categories: Internal Medicine, Neurology, Neurosurgery

Keywords: decompressive craniectomy, functional outcome, ischemic stroke

\section{Introduction}

Malignant middle cerebral artery (MCA) infarction accounts for approximately $10 \%$ of all patients who present with ischemic stroke with a mortality rate up to $80 \%$ [1]. Space-occupying edema in more than $50 \%$ to $75 \%$ of the middle cerebral artery region is known as malignant cerebral infarction [2]. Decompressive craniectomy (DC) is a life-saving surgery for patients with space-occupying hemispheric infarction due to limited medical treatments [3-5]. Cerebral edema in association with infarcted brain tissue causes displacement of brain tissue and leads to an increase in intracranial pressure (ICP). This secondary damage can be prevented by DC, which generates compensatory space to contain the swollen brain. The initial symptoms and signs of MCA occlusion are hemiparesis, hemiplegia, visual problems, and altered consciousness [6]. However, these patients worsen rapidly within the first 48 hours due to the presence of mass effect that can have serious consequences [7]. Intensive medical management with osmotic diuretics, sedation, hypothermia, hyperventilation, and mechanical ventilation have been unsuccessful so far, with an $80 \%$ reported mortality rate despite medical management [8-9].

Early critics documented the poor functional outcome of DC, particularly with dominant hemisphere involvement, resulting in a higher percentage of surviving patients who were dependent on caregivers, increasing their burden. In addition, the surgical complications and the cosmetic malformations were undesirable. Neurosurgeons may be hesitant to perform this procedure due to the lack of literature available on functional outcomes after DC. Recently, the pooled analysis of three small randomized trials (RCTs) showed that decompressive craniectomy can decrease mortality and morbidity associated with malignant infarction of the MCA [10]. Three renown RCTs, the French DECIMAL (the DEcompressive Craniectomy In MALignant MCA Infarction) trial, the Dutch HAMLET (Hemicraniectomy After Middle Cerebral Artery infarction with Life-threatening Edema Trial), and the German DESTINY (Decompressive Surgery for the Treatment of Malignant Infarction of the Middle Cerebral Artery) trial, demonstrated a major decline in mortality rates and improvement in functional outcome in patients managed with DC as compared to medical therapy [11-13]. Our study was conducted to compare the difference in functional outcomes in terms of mortality rate at 30 days and functional outcome at discharge, three months, and six months following DC for the treatment of malignant MCA infarction and medical treatment, as well as to study the association of factors influencing the outcome in patients treated with DC.

\section{Materials And Methods}

\section{Study design}

A longitudinal cohort study of patients diagnosed with malignant MCA territory infarction admitted to the neurosurgery department of Shifa International Hospital, Islamabad, Pakistan between July 2015 and November 2016 was performed. Data were collected from patients' medical, surgical, and radiological imaging records. A total of 125 patients between the ages of 18 and 65 years were included in this study. All patients had a clinical diagnosis of stroke according to the World Health Organization (WHO) stroke criteria [14]. Malignant MCA territory infarction was defined as an infarct of at least two-thirds of the MCA region with space-occupying cerebral edema and mass effect on non-contrasted computed tomographic (CT) imaging of the brain. Pretreatment clinical evaluation was based on the Glasgow Coma Scale (GCS). Inclusion and exclusion criteria are shown in Table 1. Surgical treatment consisted of $10 \times 12 \mathrm{~cm}$ diameter standardized DC with duraplasty. All patients were shifted in the neurosurgery intensive care unit (ICU) after surgery for an approximate duration of 24 - 48 hrs, and the decision regarding weaning of therapy was based on clinical as well as serial CT scan 


\section{Cureus}

and magnetic resonance imaging (MRI) findings.

\section{Inclusion Criteria}

Age between 10 - 60 years

National Institutes of Health Stroke Scales (NIHSS) $>15$

Infarct $>50 \%$ of the MCA territory (or approximately $>145$ ccs)

Decompressive craniectomy done within $12-48$ hours of symptom onset

Written informed consent by the patient or legal representative

Decrease in level of consciousness (NIHSS $\geq 1$ in 1a level of consciousness)

Glasgow Coma Scale scores (GCS) $\leq 8$

Exclusion Criteria

Age $<10$ and $>60$ years

Life expectancy $<3$ years

Both pupils fixed and dilated

Pre-existing significant disability $(m R S>2)$

Significant contralateral infarct

Glasgow coma scale (GCS $\geq 9$ )

Significant contralateral infarction

Pregnancy

Contraindications of anesthesia

\section{TABLE 1: Eligibility Criteria}

MCA: middle cerebral artery; mRS: modified Rankin Scale

\section{Data collection}

We collected data, such as age, sex, past medical history, distribution of the infarction, affected hemispheric dominance, National Institutes of Health Stroke Scale (NIHSS), modified Rankin Scale (mRS) and modified Barthel Index (mBI) scores. Informed consent was taken from patients before participation in the study. Approvals from the institutional review board and ethical committee of Shifa International Hospital, Islamabad, Pakistan were obtained for this cohort study (approval \#486-336-2016).

\section{Outcome measurements}

The outcome on follow-up was analyzed during outpatient department (OPD) visits in the 
stroke clinic and/or telephonically at three, six, and 12 months. Patients' outcomes were defined by rating the activities in their daily life with measurements established in stroke research by the mRS, NIHSS, and $\mathrm{mBI}$. The $\mathrm{mBI}$ score of $\geqslant 60$ and an $\mathrm{mRS}$ score of 3 or less were taken as favorable outcomes characterized by minimal-to-moderate disability, whereas an $\mathrm{mBI}$ less than 60 and an mRS of 4-6 define poor outcomes with moderately severe or very severe disability [15].

\section{Statistical analysis}

Sample size calculation was done using power and sample size calculation software [16], with a level of significance $(\alpha)$ of 0.05 and a power of 0.80 . Data entry and analysis were done using the Statistical Package for Social Sciences (SPSS) Software, version 22 (IBM Corp., NY, USA). Paired sample T-test at admission and at six months was used to determine significant differences in functional outcome scores and motor power of all limbs. Logistic regression and chi-square analysis were used to appreciate differences at admission, discharge, and at one, three, and six months between mRS, Barthel index, and motor power of the upper and lower limbs. A Spearman's correlation was run to determine the relationship time to surgery with the duration of ICU stay and duration of hospital stay.

\section{Results}

Data from a total of 34 patients was reviewed and analyzed. Out of these, 31 were selected while three were lost to follow-up. Twenty of the 31 patients (64.5\%) were males while 11/31 (35.5\%) were females. The mean age of all patients was $51.61 \pm 13.96$ years. The mean time to surgery was $60.61 \pm 49.83$ hours. Out of 31 patients, 18 (58.1\%) had right middle cerebral artery infarcts (RMCAI) and 13 (41.9\%) had left middle cerebral artery infarcts (LMCAI). The total hospital mortality rate was found to be $3 / 31$ (8.7\%). The mean duration of hospital stay was 15.5 \pm 11.5 days. The mean number of days spent in intensive care unit (ICU) was $4.00 \pm 2.58$ (Table 2). A total of 23 patients were put on a mechanical ventilator at some point during their stay in the hospital. The mean number of hours on mechanical ventilator of these patients was calculated to be $58.48 \pm 59.08$. 


\section{Cureus}

Gender (N = 31)

Male Females

$20(64.5 \%) 11(35.5 \%)$

Age (years)

Mean \pm standard deviation

$51.61 \pm 13.96$ years

Hemisphere Infarct $(N=31)$

Right Left

1813

Time from diagnosis to Surgery (Hours)

Mean \pm standard deviation

$60.61 \pm 49.83$ hours

Duration of Hospital Stay

Mean \pm standard deviation

$15.32 \pm 11.36$ days

Duration of ICU Stay

Mean \pm standard deviation

$4.00 \pm 2.58$ days

Rate (\%)

Mortality rate Survival rate
$8.7 \% \quad 91.3 \%$

\section{TABLE 2: Patient Characteristics}

The functional neurological scores of upper and lower limb motor power at admission, discharge, at one month, at three months, and at six months are shown in Table 3. 


\section{Cureus}

\begin{tabular}{|c|c|c|c|c|c|c|}
\hline Duration & mRS & GCS & $\begin{array}{l}\text { Modified Barthel } \\
\text { Index }\end{array}$ & NIHSS & $\begin{array}{l}\text { Motor Power } \\
\text { Upper Limb }\end{array}$ & $\begin{array}{l}\text { Motor Power } \\
\text { Lower Limb }\end{array}$ \\
\hline At Admission & $4.71 \pm 0.46$ & $9.52 \pm 2.36$ & $17.42 \pm 9.65$ & $17.10 \pm 3.22$ & $0.42 \pm 0.76$ & $0.90 \pm 1.04$ \\
\hline At Discharge & $4.10 \pm 0.307$ & $11.74 \pm 3.66$ & $31.77 \pm 13.01$ & $12.52 \pm 2.57$ & $0.45 \pm 0.62$ & $0.77 \pm 0.669$ \\
\hline $\begin{array}{l}\text { At One } \\
\text { Month }\end{array}$ & $4.06 \pm 0.25$ & $12.06 \pm 3.40$ & $42.58 \pm 13.22$ & $11.90 \pm 2.33$ & $0.74 \pm 0.68$ & $1.19 \pm 0.19$ \\
\hline $\begin{array}{l}\text { At Three } \\
\text { Months }\end{array}$ & $4.03 \pm 0.32$ & $12.26 \pm 3.17$ & $49.19 \pm 13.73$ & $11.13 \pm 2.62$ & $1.19 \pm 0.79$ & $1.42 \pm 0.81$ \\
\hline $\begin{array}{l}\text { At Six } \\
\text { Months }\end{array}$ & $4.03 \pm 0.31$ & $12.35 \pm 3.09$ & $55.65 \pm 13.46$ & $10.45 \pm 2.23$ & $2.03 \pm 1.02$ & $2.65 \pm 1.08$ \\
\hline
\end{tabular}

TABLE 3: Functional Neurological Scores of Upper and Lower Limb Motor Power at Admission, Discharge, at One Month, at Three Months, and at six months

mRS: modified Rankin Scale; GCS: Glasgow coma scale; NIHSS: The National Institutes of Health Stroke Scale

At the time of discharge, 18/31 (51.8\%) had dysarthria and 11/31 (35.5\%) had aphasia. After one month, 16/31 (51.6\%) had dysarthria and 10/31 (32.3\%) had aphasia. After three months, 6/31 (19.4\%) had dysarthria and 5/31 (16.1\%) had aphasia. After six months follow-up, 4/31 (12.9\%) had dysarthria and 2/31 (6.4\%) had aphasia. Changes of upper and lower limb motor power with the passage of time are shown in Figure 1.

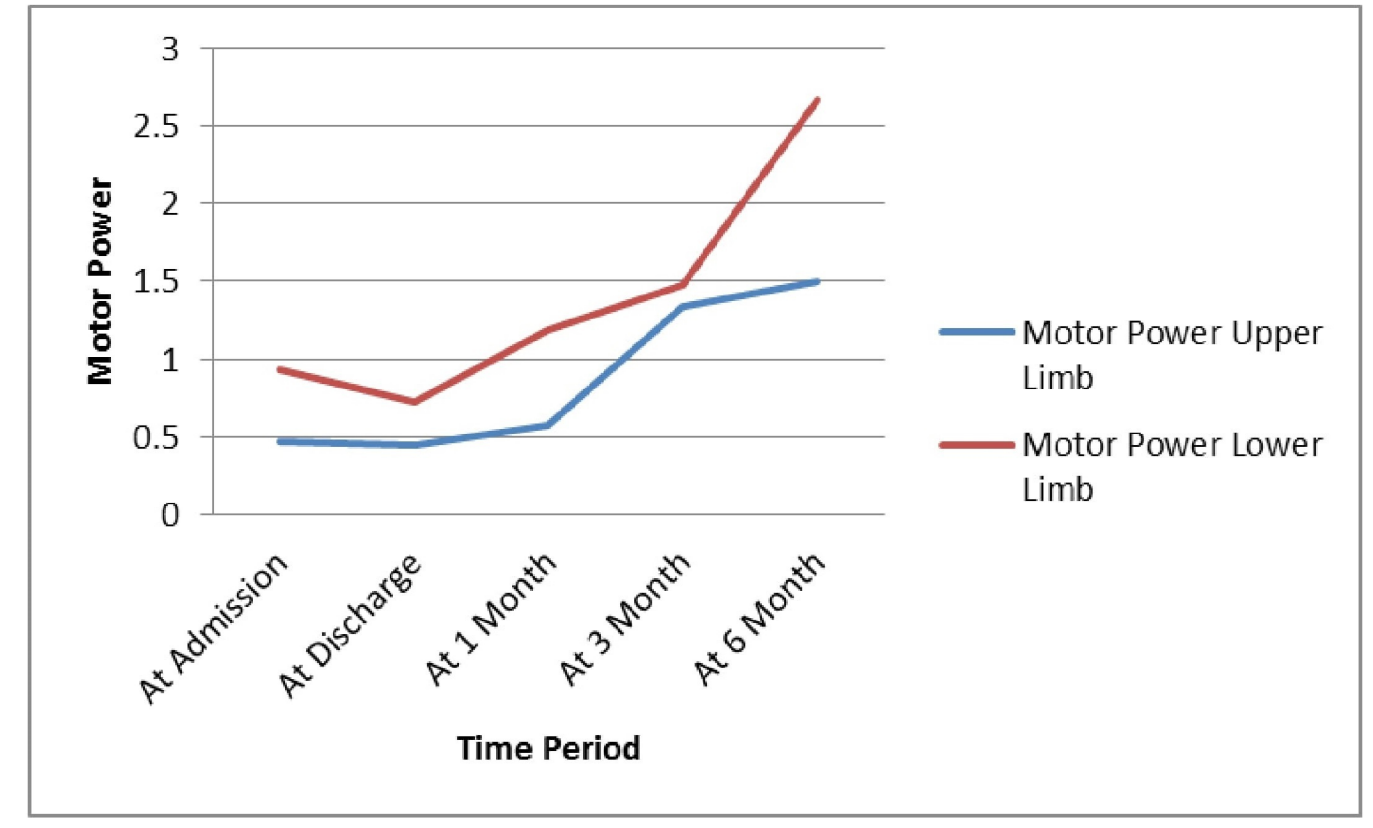

FIGURE 1: Changes of Upper and Lower Limb Motor Power with Passage of Time 


\section{Cureus}

Logistic regression was applied to assess the association between the type of MCA infarct with mRS, GCS, NIHSS, modified Barthel Index, and upper and lower limb motor power. The logistic regression model was not statistically significant $\chi 2(4)=3.896, p=0.866$. Pair-sample T-test was done to assess for any change in neurological score and upper and lower limb motor power at admission and six months after discharge. There was a statistically significant improvement of neurological scores and upper and lower motor power over a course of six months after treatment $(\mathrm{p}<0.001)$ with poor functional outcomes $(\mathrm{mRS}>4$ and $\mathrm{mBI}>60)$ (Table 4$)$.

\begin{tabular}{|c|c|c|c|c|c|}
\hline \multirow[t]{2}{*}{ Neurological Scores } & \multirow[t]{2}{*}{$\begin{array}{l}\text { Mean } \\
\text { Difference } \pm \text { SD }\end{array}$} & \multicolumn{2}{|c|}{$\begin{array}{l}95 \% \text { Confidence Interval of } \\
\text { the Difference }\end{array}$} & \multirow[t]{2}{*}{$\begin{array}{l}\text { t- } \\
\text { value }\end{array}$} & \multirow[t]{2}{*}{$\begin{array}{l}\text { P- } \\
\text { value* }\end{array}$} \\
\hline & & Lower Limbs & Upper Limbs & & \\
\hline $\begin{array}{l}\mathrm{mRS} \text { at admission and at six months after } \\
\text { discharge }\end{array}$ & $0.68 \pm 0.54$ & .479 & .876 & 6.97 & $\begin{array}{l}< \\
0.001\end{array}$ \\
\hline $\mathrm{mBI}$ at admission and at six months after discharge & $-38.23 \pm 11.66$ & -42.502 & -33.950 & - & $\begin{array}{l}< \\
0.001\end{array}$ \\
\hline $\begin{array}{l}\text { NIHSS at admission and at six months after } \\
\text { discharge }\end{array}$ & $6.65 \pm 3.49$ & 5.365 & 7.924 & 10.61 & $\begin{array}{l}< \\
0.001\end{array}$ \\
\hline GCS at admission and six months after discharge & $-2.84 \pm 2.58$ & -3.786 & -1.89 & -6.12 & $\begin{array}{l}< \\
0.001\end{array}$ \\
\hline $\begin{array}{l}\text { Motor power of upper limb at admission and six } \\
\text { months after discharge }\end{array}$ & $-1.61 \pm 1.26$ & -2.074 & -1.152 & -7.15 & $\begin{array}{l}< \\
0.001\end{array}$ \\
\hline $\begin{array}{l}\text { Motor power of lower limb at admission and six } \\
\text { months after discharge }\end{array}$ & $-1.74 \pm 1.41$ & -2.260 & -1.223 & -6.86 & $\begin{array}{l}< \\
0.001\end{array}$ \\
\hline
\end{tabular}

\section{TABLE 4: Comparison of Different Neurological Functional Scores at Admission and} After Six Months of Discharge

${ }^{*} \mathrm{P}$-value derived from paired sample t-test

mBI: modified Barthel Index; mRS: modified Rankin Scale; GCS: Glasgow coma scale; NIHSS: The National Institutes of Health Stroke Scale

A Spearman's correlation was run to determine the relationship time to surgery with duration of ICU stay and duration of total hospital stay. There was a strong negative correlation between time from diagnosis to surgery and duration of ICU stay, which was statistically significant (rs = $-0.429, \mathrm{p}=0.020$ ). No statistically significant relationship was found between time to surgery and duration of hospital stay ( $\mathrm{rs}=-0.230, \mathrm{p}=0.221$ ). One-way analysis of variance (ANOVA) was applied to look for an association between the time from diagnosis to surgery and language impairment, and it showed no significant association $(F=0.613, p>0.05)$. Of the three patients that expired, two were males and one was female. Among the expired patients, one patient had a right-sided MCA, whereas the other two had left-sided MCA cerebral infarcts. All three patients had an mRS at admission of 5 and a mean GCS of $7.67 \pm 2.082$. 


\section{Discussion}

The imperative role of DC in the survival of patients with malignant MCA infarction is widely accepted. Several randomized controlled trials have demonstrated a decrease in mortality of patients undergoing DC [11-13]. However, the issue more pertinent to current researchers is whether this life-saving surgery improves the quality of life and functional outcome of surviving patients. The results of our study demonstrate improvement in the neurological outcomes at one, three, and six months on mRS, mBI, GCS, and NIHSS scale, but the overall functional outcome of our patients was still graded as poor according to the mBI (less than 60) and mRS scale (>4) at follow-up [14-15]. The major factors affecting functional outcome after the surgery include the timing of the surgery, preoperative condition of the patient, and the age of the patient [16]. The ideal time for undertaking the surgery should be within 48 hours of the onset of the stroke [17-18]. Also, severe neurological deficits at the time of admission and old age are considered to be bad prognostic factors for the long-term functional outcome after DC [19]. The mean time from diagnosis to surgery in our study was 60.61 hours, which may be the probable explanation for the relatively poor outcome of our patients on $\mathrm{mBI}$ and $\mathrm{mRS}$ at six months of follow-up. Despite the fact that the majority of our patients fall into the ideal age category for DC, severe neurological insufficiency at the time of admission and longer duration of mechanical ventilation may be responsible for the relatively poor functional outcome on various neurological scales [20].

One of the striking findings of our study is the considerable improvement in the motor power of both upper and lower limbs, but more so in the lower limbs. Carter, et al. concluded that the one-year outcome in the majority of their patients was noted to be at the level of nearindependence, being able to walk, and having a Barthel score greater than 60 [21]. We expect nearly the same level of functional independence in our patients. In our study, statistically significant improvements in the neurological scores, along with upper and lower motor powers, were noted after six months of DC. The prominent finding of this study is a major improvement observed in dysarthria (from $51.8 \%$ patients at admission to $12.9 \%$ after six months) and aphasia (from $35.5 \%$ at admission to $6.4 \%$ patients after three months). However, we were unable to elaborate the dominant hemisphere and the type of aphasia in individual patients.

Our results comply with other studies, including a meta-analysis by Foerch, et al. According to that study, there was a considerable decrease in the mortality and improvement of functional outcome after DC as compared to the conservative management of malignant MCA infarct. However, it was still associated with an increased incidence of major disability (mRS score: 4-5) among the survivors [22]. Further evaluation about the exact type of functional disability among the survivors needs more attention. Our findings (mRS: 4-5) are in accordance with that of Suyama, et al. who determined the mRS score at three months in about half of their patients, out of whom only a small number of patients showed a favorable functional outcome [23]. This similarity is possibly due to delay in undertaking the surgery in a significant number of patients, i.e. after 48 hours of onset of stroke and low GCS scores preoperatively. In contrast to the mean age of 51.61 years in our study, the vast majority of their patients were elderly with the mean age of 67.0 years; however, age was not established as an independent factor for mortality in that study, justifying the use of surgery in elderly patients if further evidence of functional improvement is established [23].

\section{Limitations}

Neuropsychological evaluation of the patients could not be carried out on follow-up. Previous literature shows some depressive inclination in patients after undergoing the surgery [24]. The probable reason for improved clinical and functional outcomes after DC is due to the inclusion of patients under age of 60 years as literature already documents the poor outcome of DC in malignant MCA infarcts after 60 years of age [25]. Further research needs to be done on overall 
long-term neuropsychological assessment in patients after undergoing DC for malignant MCA infarcts.

\section{Conclusions}

Decompressive craniectomy shows mild improvements in functional outcomes after six months of malignant MCA infarcts but with poor functional outcomes as a whole $(\mathrm{mRS}>4$ and $\mathrm{mBI}<$ 60). An early diagnosis is essential for DC, which has been shown to reduce mortality.

\section{Additional Information Disclosures}

Human subjects: Consent was obtained by all participants in this study. Shifa International Hospital, Islamabad, Pakistan issued approval 486-336-2016. Animal subjects: All authors have confirmed that this study did not involve animal subjects or tissue. Conflicts of interest: In compliance with the ICMJE uniform disclosure form, all authors declare the following: Payment/services info: All authors have declared that no financial support was received from any organization for the submitted work. Financial relationships: All authors have declared that they have no financial relationships at present or within the previous three years with any organizations that might have an interest in the submitted work. Other relationships: All authors have declared that there are no other relationships or activities that could appear to have influenced the submitted work.

\section{References}

1. Raffiq MAM, Haspani MSM, Kandasamy R, Abdullah JM: Decompressive craniectomy for malignant middle cerebral artery infarction: Impact on mortality and functional outcome. Surg Neurol Int. 2014, 5:102.

2. Chao SP, Chen CY, Tsai FY, Chan WP, Chen CI: Predicting mortality in patients with "malignant" middle cerebral artery infarction using susceptibility-weighted magnetic resonance imaging: preliminary findings. Medicine (Baltimore). 2016, 95:e2781. 10.1097/MD.0000000000002781

3. Subramaniam S, Hill MD: Decompressive hemicraniectomy for malignant middle cerebral artery infarction: an update. Neurologist. 2009, 15:178-84. 10.1097/NRL.0b013e3181963d19

4. Neugebauer H, Creutzfeldt CJ, Hemphill JC 3rd, Heuschmann PU, Jüttler E: DESTINY-S: attitudes of physicians toward disability and treatment in malignant MCA infarction. Neurocrit Care. 2014, 21:27-34. 10.1007/s12028-014-9956-0

5. Köhrmann M, Schwab S: Hemicraniectomy for malignant middle cerebral artery infarction. Curr Opin Crit Care. 2009, 15:125-30. 10.1097/MCC.0b013e328321826e

6. Cheung A, Telaghani CK, Wang J, Yang Q, Mosher TJ, Reichwein RK, Cockroft KM: Neurological recovery after decompressive craniectomy for massive ischemic stroke . Neurocrit Care. 2005, 3:216-23. 10.1385/NCC:3:3:216

7. Qureshi AI, Suarez JI, Yahia AM, Mohammad Y, Uzun G, Suri MF, Zaidat OO, Ayata C, Ali Z, Wityk RJ: Timing of neurologic deterioration in massive middle cerebral artery infarction: a multicenter review. Crit Care Med. 2003, 31:272-77. 10.1097/00003246-200301000-00043

8. Wartenberg KE: Malignant middle cerebral artery infarction. Curr Opin Crit Care. 2012, 18:152-63. 10.1097/MCC.0b013e32835075c5

9. Thomalla GJ, Kucinski T, Schoder V, Fiehler J, Knab R, Zeumer H, Weiller C, Röther J: Prediction of malignant middle cerebral artery infarction by early perfusion- and diffusionweighted magnetic resonance imaging. Stroke. 2003, 34:1892-99. 10.1161/01.STR.0000081985.44625.B6

10. Vahedi K, Hofmeijer J, Juettler E, Vicaut E, George B, Algra A, Amelink GJ, Schmiedeck P, Schwab S, Rothwell PM, Bousser MG, van der Worp HB, Hacke W; DECIMAL, DESTINY, and HAMLET investigators: Early decompressive surgery in malignant infarction of the middle cerebral artery: a pooled analysis of three randomised controlled trials. Lancet Neurol . 2007, 6:215-22. 10.1016/S1474-4422(07)70036-4 
11. Hofmeijer J, Kappelle LJ, Algra A, Amelink GJ, van Gijn J, van der Worp HB; HAMLET investigators: Surgical decompression for space-occupying cerebral infarction (the Hemicraniectomy After Middle Cerebral Artery infarction with Life-threatening Edema Trial [HAMLET]): a multicentre, open, randomised trial. Lancet Neurol. 2009, 8:326-33. 10.1016/S1474-4422(09)70047-X

12. Vahedi K, Vicaut E, Mateo J, Kurtz A, Orabi M, Guichard JP, Boutron C, Couvreur G, Rouanet F, Touzé E, Guillon B, Carpentier A, Yelnik A, George B, Payen D, Bousser MG; DECIMAL Investigators: Sequential-design, multicenter, randomized, controlled trial of early decompressive craniectomy in malignant middle cerebral artery infarction (DECIMAL Trial). Stroke. 2007, 38:2506-17. 10.1161/STROKEAHA.107.485235

13. Jüttler E, Schwab S, Schmiedek P, Unterberg A, Hennerici M, Woitzik J, Witte S, Jenetzky E, Hacke W; DESTINY Study Group: Decompressive Surgery for the Treatment of Malignant Infarction of the Middle Cerebral Artery (DESTINY): a randomized, controlled trial.. Stroke. 2007, 38:2518-25. 10.1161/STROKEAHA.107.485649

14. Hao Z, Chang X, Zhou H, Lin S, Liu M: A cohort study of decompressive craniectomy for malignant middle cerebral artery infarction: A real-world experience in clinical practice. Medicine (Baltimore). 2015, 94:e1039. 10.1097/MD.0000000000001039

15. Merenda A, DeGeorgia M: Craniectomy for acute ischemic stroke: how to apply the data to the bedside. Curr Opin Neurol. 2010, 23:53-58. 10.1097/WCO.0b013e328334bdf4

16. Dupont WD, Plummer WD Jr: Power and sample size calculation; a review and computer program. Control Clin Trials. 1998, 11:116-28. 10.1016/0197-2456(90)90005-M

17. Tsai CL, Chu H, Peng GS, Ma HI, Cheng CA, Hueng DY: Preoperative APACHE II and GCS scores as predictors of outcomes in patients with malignant MCA infarction after decompressive hemicraniectomy. Neurol India. 2012, 60:608-12. 10.4103/0028-3886.105195

18. Uhl E, Kreth FW, Elias B, Goldammer A, Hempelmann RG, Liefner M, Nowak G, Oertel M, Schmieder K, Schneider GH: Outcome and prognostic factors of hemicraniectomy for space occupying cerebral infarction. J Neurol Neurosurg Psychiatry. 2004, 75:270-74.

19. Yang MH, Lin HY, Fu J, Roodrajeetsing G, Shi SL, Xiao SW: Decompressive hemicraniectomy in patients with malignant middle cerebral artery infarction: A systematic review and metaanalysis. Surgeon. 2015, 13:230-40. 10.1016/j.surge.2014.12.002

20. Cho DY, Chen TC, Lee HC: Ultra-early decompressive craniectomy for malignant middle cerebral artery infarction. Surg Neurol. 2003, 60:227-32. 10.1016/S0090-3019(03)00266-0

21. Carter BS, Ogilvy CS, Candia GJ, Rosas HD, Buonanno F: One-year outcome after decompressive surgery for massive nondominant hemispheric infarction. Neurosurgery. 1997, 40:1168-75. 10.1097/00006123-199706000-00010

22. Foerch C, Lang JM, Krause J, Raabe A, Sitzer M, Seifert V, Steinmetz H, Kessler KR : Functional impairment, disability, and quality of life outcome after decompressive hemicraniectomy in malignant middle cerebral artery infarction. J Neurosurg. 2004, 101:248-54. 10.3171/jns.2004.101.2.0248

23. Suyama K, Horie N, Hayashi K, Nagata I: Nationwide survey of decompressive hemicraniectomy for malignant middle cerebral artery infarction in Japan. World Neurosurg. 2014, 82:1158-63. 10.1016/j.wneu.2014.07.015

24. Leonhardt G, Wilhelm H, Doerfler A, Ehrenfeld CE, Schoch B, Rauhut F, Hufnagel A, Diener HC: Clinical outcome and neuropsychological deficits after right decompressive hemicraniectomy in MCA infarction. J Neurol. 2002, 249:1433-40. 10.1007/s00415-002-0875-1

25. Heiss WD: Malignant MCA infarction: Pathophysiology and imaging for early diagnosis and management decisions. Cerebrovasc Dis. 2016, 41:1-7. 10.1159/000441627 